\title{
CORRESPONDENCE
}

\section{Licking Darwin}

SIR - How absurd to hold that Darwinism cannot be falsified. All it would take is a single clear demonstration of the de novo creation of a complex organism, well adapted to its environment, and the Darwinists would be legless.

G.P. VINSON

Department of Biochemistry and Chemistry, The Medical College of St Bartholomew's Hospital, London ECI, UK

\section{Weed control}

SIR - As May emphasizes ${ }^{1}$, all possible steps should be taken to prevent the intrusion of noxious weeds into new regions. That article paid rather less adequate attention to weeds that are aiready established. Consider two hypothetical situations. Suppose it was discovered that one of these weeds contained a valuable fibre. Within a few years we would have a conservation programme to save the weed from extinction. Suppose enterprising adolescents found that one of the weeds contained a hallucinogen. The $\$ 15$ million quoted as the annual cost of water hyacinth control in Florida and Louisiana would be "chicken feed" compared with what drug control authorities would spend on elimination.

Water hyacinth has been studied for so long that components as dramatic as these are unlikely to be found in it. Nevertheless, it is a prodigious producer of biomass and is often conveniently located on broad areas of water from which mechanical collection is easy. Twenty one years ago $^{2}$ I made " . . . a plea for some reorientation of thinking in areas suffering from, or threatened with, water hyacinth. There is a case for directing some research towards finding uses for the pest instead of concentrating all efforts on its eradication."

Since then, the pest has made great headway. Less headway has been made on finding uses for it. Interest is, however, increasing. Chibbar and Singh ${ }^{3}$ fed cows on silage made from water hyacinth and paddy straw, and there have been several recent papers in the Indian Journal of Animal Science extending that work. Hyacinth is deliberately cultivated in China for pig feed. It is a component of the mixtures used for biogas fermentation in many countries. These and other uses are surveyed in Making Aquatic Weeds Useful (US National Academy of Sciences, 1976) and in Handbook of Utilization of Aquatic Plants (Food and Agricultural Organization, 1979). This is encouraging. But the amount of effort put into finding uses for water hyacinth and other weeds is a tiny fraction of the effort put into killing them. I do not suggest deliberate encouragement, only the assignment of comparable importance to both lines of approach.

Harpenden, Herts, UK

N.W. PIRIE

1. May, R.M. Nature 290, 85-86 (1981)

\section{Cafeteria feeding}

SIR - I wonder if I am alone in my dislike of the term "cafeteria feeding" used first, I think, by Rothwell and Stock in 1979 (Rothwell, H.J. \& Stock, M.J. Nature 281, 31; 1979). According to the Concise Oxford Dictionary a cafeteria is a "restaurant in which customers fetch food and drink from a counter" which is hardly an accurate description of the behaviour of rats allowed to make their own choice of palatable items of food. I would like to suggest that, before it is too late, editors of scientific journals ask authors to use a more accurate description, for example to replace "cafeteria diet" by "a selfselected palatable diet" (abbreviated SSPD) or other equivalent term.

University of Bristol, UK

A.S. COLE

\section{Cancer causation}

SIR - The recent series of articles ${ }^{1-3}$ on cancer causation prompts me to respond. Without defending Epstein and Swartz, I would like to offer several alternative explanations to some of the examples which Cairns used to argue his case that somatic mutations play little or no part in human carcinogenesis.

Although Cairns' novel hypothesis is to be welcomed as a stimulus to new experimental approaches, I feel that he has summarily dismissed a significant amount of evidence consistent with the somatic mutations theory of cancer. Furthermore, carcinogenesis is a multi-step process and there are probably several distinct molecular mechanisms that can "cause" and influence carcinogenesis, not the least of which are somatic mutations ${ }^{4}$.

Specifically, Cairns argues that the apparent lack of common fatal cancers in xeroderma pigmentosum (XP) individuals (the cells from whom lack proper DNA repair causing them to be hypermutable to many mutagens, including the ultraviolet component of sunlight) is evidence that the production of mutations in XP cells is probably irrelevant to carcinogenesis. There are at least two reasonable alternative explanations why XP ratients rarely get cancers other than skin tumours $^{5}$. The XP patients normally do not live iong enough to manifest these internal tumours (an explanation cited but dismissed by Cairns) and most cancers are the result of initiation (mutagenesis) and promotion (amplification of an initiated cell into a clone where additional genetic or epigenetic changes can occur). One can explain the production of skin tumours in XP on this hypothesis since, using this concept, repaired sunlight-induced lesions in the skin cells of XP patients will lead to both cell killing and mutated viable cells.

In effect, the large numbers of killed cells will "force" the surviving, but initiated, cells to repopulate the necrotic tissue, giving rise to clones of dysfunctional cells. During that repopulation phase, some of these initiated cells are further exposed to more mutagens. Thus, the cytotoxicity caused by the inability to repair large amounts of sunlight-induced DNA damage can be considered an "indirect promoter", much in the manner of a partial hepatectomys. On the other hand, internal cells of XP patients, which are exposed to chemical mutagens that mimic sunlightinduced DNA damage, probably are not exposed to high enough levels constantly to cause significant cell killing, as occurs in the skin. In effect, these initiated cells will not be promoted! Only after long periods of time or exposure to chronic effective levels of exogenous or endogenous tumour promoters will internal tumours appear.

A second argument used by Cairns to support this thesis of genetic transposition was the discussion on Bloom's syndrome. I agree with Cairns that Bloom's syndrome might be a "better" model for studying carcinogenesis, but for a different reason. At the time of writing his paper, Cairns was not aware of the observation that Bloom's syndrome seems to be a "mutator" syndrome 6 , in that it spontaneously generates mutations in their somatic tissue. In effect, Bloom's cells can generate mutations in any proliferation cell of the body, with or without exposure to "environmental" mutagens. This would explain the wide range of tumours (and other clinical features) associated with the syndrome, and would also fit the initiation/ promotion model, since each time a spontaneous mutant cell arises and then divides, it can enhance the probability of additional genetic imbalances.

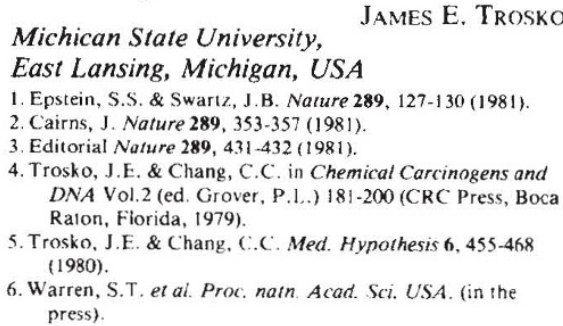

\section{Genes and free will}

SIR - Asked to dissociate themselves from the neo-Nazi use of their names and theories, John Maynard Smith' and Richard Dawkins 2 have both done so. Professor Maynard Smith's unequivocal couple of sentences will be no surprise to scientists who know him as a man of principle and integrity; his letter will give no comfort to the National Front or any similar grouping.

It is a pity, though, that Dr Dawkins appears to think that the issue I sought to raise in my letter is of a parallel with the relatively harmless debate on cladistics and dialectics which has kept us entertained over recent months. If it were not for that dreary little edge of "reds under the bed" of which Stephen Jay Gould reminds us ${ }^{3}$, I suspect we could look forward to Nature with the same enthusiasm as once we had for Beano. However, the issues are not the same. Racism directly haunts the streets of our cities. In our laboratories neither Dawkins nor I live in the daily hazard that the obscene rubbish of the New Nation and its followers fosters in the East End or New Cross. When Dawkins disdains the ephemera of mere "human politics", or accuses his critics of being as guilty as the Nazis of dragging the elegant purity of his neo-Darwinsim into the litter of the city streets, he does so at the peril of a repetition of the tragedies of the 1930 s.

Of course we must all beware of the fallacy Continued on page 432 